\title{
Preference in Floor Type Among Dutch Elite Male Handball Players: The Role of Different Floor Characteristics
}

\author{
Thom PMJ Vluggen, $M D^{1^{*}}$, Simone E Heijnen, $M D^{1}$, Martijn GM Schotanus, $P h D^{1}$, Rian AJ Dekker, $M S c^{2}$, \\ Bart GCJ Wijers ${ }^{3}$ and Edwin JP Jansen, MD, PhD
}

${ }^{1}$ Department of Orthopedic surgery, Zuyderland Medical Centre, The Netherlands

${ }^{2}$ Medi-Sport, Physiotherapy and Training, Geleen, The Netherlands

${ }^{3}$ Terra Sports Technology, Sittard-Geleen, The Netherlands

\begin{abstract}
Purpose: This study assessed the preference for indoor floor types among Dutch male elite handball players: Area- vs. point elastic floors. Secondly, to compare floor characteristics between area elastic and point elastic indoor sports fields in the Dutch elite league.

Methods: The preference in floor type was questioned in an online survey by ranking the indoor floors of the Dutch elite league. Floor characteristics (shock absorption, vertical deformation, energy restitution) of all surfaces in the Dutch elite league were measured using the Advanced Artificial Athlete apparatus. Floor characteristics were compared between area- and point elastic floors.

Results: Eighty-eight subjects responded to the online survey. The top 4 ranked surfaces among Dutch elite league handball players were area elastic; the other six surfaces were point elastic. Shock absorption differed significantly $(p=$ 0.014): $57.5 \%$ versus $27.9 \%$ for area elastic and point elastic floors, respectively. Vertical deformation differed significantly $(p=0.014): 4.5 \mathrm{~mm}$ versus $1.9 \mathrm{~mm}$ for area and point elastic floors, respectively. Energy restitution differed significantly $(p=0.050): 47.8 \%$ versus $62.9 \%$ for area and point elastic floors, respectively.

Conclusion: Male handball players active in the Dutch elite league, prefer to play on area elastic floors compared to point elastic floors, possibly due to differences in floor characteristics between area and point elastic floors: Higher shock absorption, higher vertical deformation and lower energy restitution in favour of the area elastic floors. These findings are most likely related to an increased injury prevalence on point elastic floors as has been investigated previously and is possibly an important point of application to effectuate a reduction in injury rates in professional handball.
\end{abstract}

\section{Keywords}

Floor preference, Floor characteristics, Area elastic, Point elastic, Dutch handball

\section{Introduction}

Handball players endure high mechanical stresses on the joints, contributing handball to be one of the most vulnerable sports for developing injuries [1-4]. In particular, ankle sprains and anterior cruciate ligament $(A C L)$ tears appear to be the most common type of acute injuries [5-8]. Besides, overuse seems to be an important mechanism in developing injuries in handball that affect shoulder and knee most of the time [5]. Therefore, it is important to analyse risk factors for developing injuries in handball in order to apply possible preventive measures $[7,9,10]$.

Injury prevalence among handball players depends on the type of floor they play. $A C L$ injuries in female handball players appear to be higher on point elastic (e.g. rubber or linoleum) floors compared to area elastic (e.g. wooden) floors [11]. Pasanen, et al. Compared injury risk between area and point elastic floors in Finnish female floorball. They found a

*Corresponding author: Thom Vluggen, Department of Orthopedic surgery, Zuyderland Medical Centre, The Netherlands

Accepted: November 23, 2020

Published online: November 25, 2020

Citation: Vluggen TPMJ, Heijnen SE, Schotanus MGM, et al. (2020) Preference in Floor Type Among Dutch Elite Male Handball Players: The Role of Different Floor Characteristics. Arch Sports Med 4(2):240-244 
Citation: Vluggen TPMJ, Heijnen SE, Schotanus MGM, et al. (2020) Preference in Floor Type Among Dutch Elite Male Handball Players: The Role of Different Floor Characteristics. Arch Sports Med 4(2):240-244

Table 1: Questions asked in the online survey translated in english.

\begin{tabular}{|l|l|}
\hline 1. & What is your age? \\
\hline 2. & How many years of experience do you have in the Dutch elite League? \\
\hline 3. & What team contracted you during season $2012 / 2013$ ? \\
\hline 4. & What is the surface material of your home court (wooden or linoleum)? \\
\hline 5. & Rank the 10 floors in the Dutch elite League with ' 1 ' as best floor and ' 10 ' as worst floor (Ranking home court is not possible). \\
\hline
\end{tabular}

higher risk for non-contact injuries and a higher prevalence of $\mathrm{ACL}$ injuries on point elastic floors compared to area elastic floors [12]. However, preference for one of these floor types among professional handball players has never been investigated. Nor the exact differences in surface characteristics between area elastic and point elastic floor types have ever been examined.

The purpose of this study is two fold: 1 . Assess the preference in floor type among Dutch male elite handball players. 2. Compare floor characteristics between area and point elastic handball floors in the Netherlands. We hypothesize professional handball players prefer to play on area elastic floors. Besides, we hypothesize floor characteristics differ between area elastic and point elastic floor types.

\section{Materials \& Methods}

\section{Study design}

This prospective study, approved by the local Institutional Review Board (METC Zuyd, Nr.: 13N103), was in compliance with both the Helsinki Declaration of 1975 and guidelines for Good Clinical Practice. Between February and March 2013 an online survey (Monkey, Palo Alto $C A$ ) was conducted to assess preference in floor type among Dutch elite handball players. Besides, floor characteristics in the Dutch elite league were measured using an Advanced Artificial Athlete (Triple-A) apparatus.

\section{Online survey}

All teams in the Dutch elite league were approached by mail or phone to fill out an online survey. Informed consent was given by coaches and contact persons of each team. The online survey was sent to the team doctor or physiotherapist. Participants had to complete the online survey within 2 months. Inclusion criteria were: Male, older than 18 years, active in the highest national Dutch elite league during season 2012/2013, and being part of the selection. Players were excluded if they did not match inclusion criteria, were substitutes joining the selection once in a while, or did not understand the Dutch language. Table 1 shows the online survey. This questionnaire measures preference of floor type and what players think is the best and worst floor in the league, based on their personal experiences. Players were not allowed to vote for their home court to avoid bias.

\section{Floor characteristics}

Floor characteristics of the indoor sports fields in the Dutch elite handball league are normally measured and calculated according EN 14808, shock absorption and EN 14809,
Vertifical deformation. However, in this study the Advanced Artificial Athelete (AAA) is used to test the indoor floors using the regular flat test foot [13]. At the AAA the shock absorption and vertical deformation are measured and calculated at the same impact test by using an accelerator sensor. This is not the case in EN14808 and EN14809 where the vertical deformation is tested with another test set up compared to the shock absorption test. Exact test methods are described in FIFA Quality Concept for football turf [13]. In this study 3 floor characteristics of each floor in the league were measured: 1 . Shock absorption, 2. Vertical deformation, and 3. Energy restitution. Measurements took place on 6 different field locations: Each corner, the centre and the goal area. Shock absorption is defined as the ratio between the maximum force during impact on the sport surface and the maximum force during impact on concrete flooring, given in \%. Vertical deformation is defined as surface compression in millimetres during that maximum impact. Energy restitution is defined as return of kinetic energy derived from the surface into the device (in real life into the human body), given in \%. The Triple-A apparatus has a drop mechanism with an accelerometer incorporated and one spring. Shock absorption, vertical deformation and energy restitution were determined by the sensor in one single drop. The device measures acceleration as a function of time during and after the drop (Figure 1). Calculating speed and position of the dropping weight by the software will result in values for above mentioned parameters. In exact terms, a 20 kg weight, containing an accelerometer, is dropped from a height of $55 \mathrm{~mm}$ and lands on a spring which states a constant force of $2000 \mathrm{~N} / \mathrm{mm}$. The maximum deceleration is a measure for the maximum force and so for the shock absorption value. The accelerometer calculates the speed at any time and contributes to calculating energy restitution by calculating the ratio of kinetic energy after and before impact. Vertical deformation is calculated by determining the position of the weight, corrected with compression of the spring at maximum impact force.

\section{Statistics}

Data were analysed using SPSS software (IBM Corp. Released 2010. IBM SPSS Statistics for Windows, Version 19.0. Armonk, NY: IBM Corp.) And tested for normality with the Shapiro-Wilk test. The parametric Student's simple t-test was used to compare groups for age, years of experience in the Dutch elite league and surface rating. Floor characteristics were not normally distributed as tested with Shapiro-Wilk test. Therefore, differences were analysed using the Mann-Whitney U test, a non-parametric variant of the Student's simple t-test. Results were considered statistically significant at $p \leq 0.05$. 
Citation: Vluggen TPMJ, Heijnen SE, Schotanus MGM, et al. (2020) Preference in Floor Type Among Dutch Elite Male Handball Players: The Role of Different Floor Characteristics. Arch Sports Med 4(2):240-244

Triple A: Force vs time graph

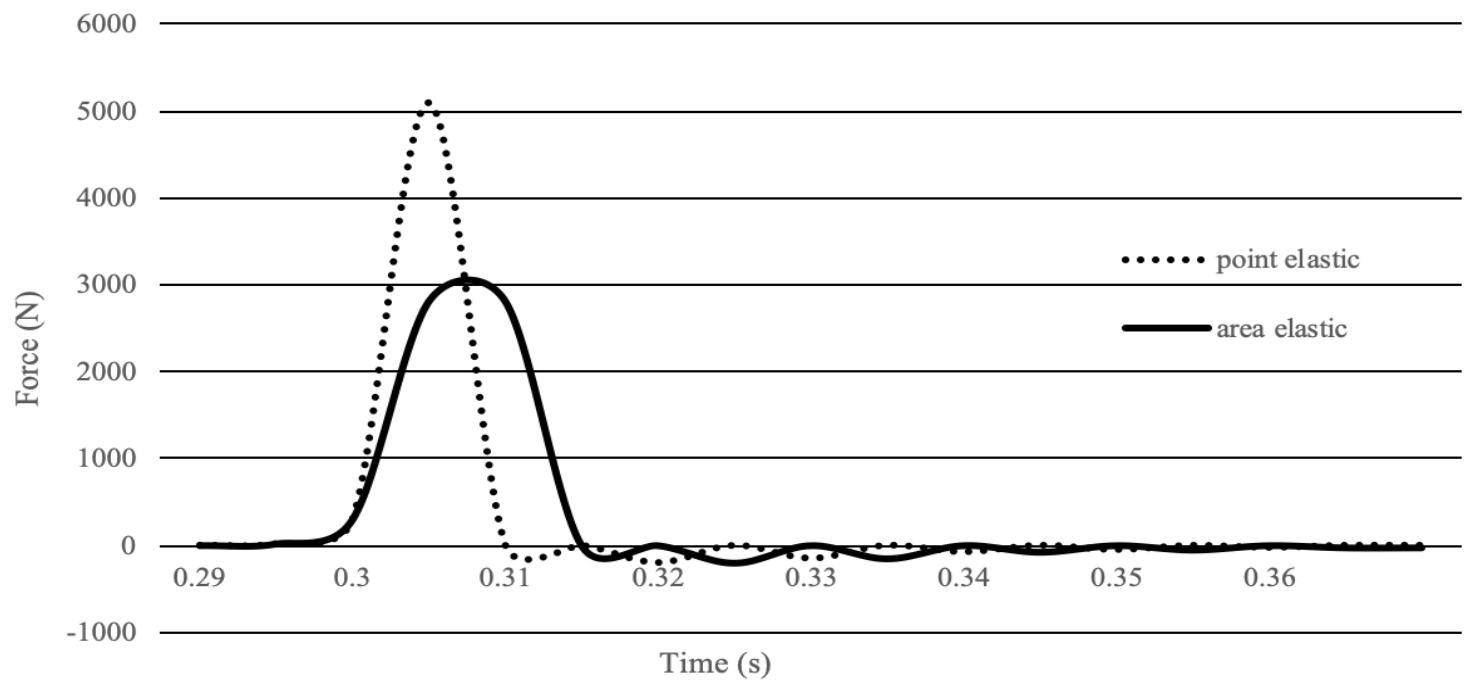

Figure 1: Force vs. time graph measured with the Advanced Artificial Athlete apparatus. The graph shows the course of the force as a function of time on the spring, as measure for maximum deceleration, generated by the weight that was dropped at 0 sec. It shows the free fall between 0.29 and 0.31 at $-1 \mathrm{G}$ (or $-200 \mathrm{~N}$ ).

Table 2: Mean scores of indoor area elastic and point elastic floors, after ranking with best score 1 and worst score 10. Also floor characteristics for each floor are summarized.

\begin{tabular}{|l|l|l|l|l|l|}
\hline Ranking & Indoor floor & Score & Shock absorption (\%) & Vertical deformation (mm) & Energy restitution (\%) \\
\hline $1^{\text {st }}$ & Area elastic & 3.5 & 55 & 4.3 & 51 \\
\hline $2^{\text {nd }}$ & Area elastic & 3.7 & 59 & 4.9 & 46 \\
\hline $3^{\text {rd }}$ & Area elastic & 4.2 & 59 & 5.0 & 54 \\
\hline $4^{\text {th }}$ & Area elastic & 4.9 & 57 & 3.6 & 40 \\
\hline $5^{\text {th }}$ & Point elastic & 5.2 & 32 & 2.5 & 63 \\
\hline $6^{\text {th }}$ & Point elastic & 5.2 & 27 & 1.5 & 50 \\
\hline $7^{\text {th }}$ & Point elastic & 5.6 & $X$ & $X$ & $X$ \\
\hline $8^{\text {th }}$ & Point elastic & 6.1 & 27 & 2.0 & 65 \\
\hline $9^{\text {th }}$ & Point elastic & 6.3 & 24 & 1.8 & 68 \\
\hline $10^{\text {th }}$ & Point elastic & 6.5 & 29.3 & 1.9 & 62 \\
\hline
\end{tabular}

\section{Results}

Eighty-eight subjects responded to the online survey. Mean age of the participants was 24.8 y $( \pm 4.2)$. The average years of experience in the Dutch elite league was 4.5 y $( \pm$ 3.5). From all the approached clubs in the Dutch elite league, 4 indoor fields were area elastic and 6 point elastic. Table 2 shows ranking of preference among the participants: The top 4 ranked surfaces were area elastic floors; the next six surfaces were point elastic floors.

Table 2 shows the floor characteristics of 9 out of 10 indoor sports fields in the Dutch elite league, including 4 area elastic floors and 5 point elastic floors. One point elastic floor was not included, because permission to measure this floor was not given. Floor characteristics differed significantly between area elastic and point elastic floors. Mean shock absorption differed significantly ( $p=0.014): 57.5 \%(55.9 \%, 59,1 \%)$ and $27.9 \%(25.3 \%, 30.5 \%)$ for area elastic and point elastic floors, respectively. Mean vertical deformation differed significantly $(p=0.014): 4.5 \mathrm{~mm}(3.9 \mathrm{~mm}, 5.1 \mathrm{~mm})$ and $1.9 \mathrm{~mm}(1.62 \mathrm{~mm}$, $2.26 \mathrm{~mm}$ ) for area elastic and point elastic floors, respectively. Also, mean energy restitution differed significantly ( $\mathrm{p}=$ 0.050): $47.8 \%(41.8 \%, 53.8 \%)$ and $61.6 \%$ (55.6\%, 67.6\%) for area elastic and point elastic floors, respectively. No significant difference was found in floor characteristics among the area elastic floors, nor among the point elastic floors.

Floor characteristics between the worst ranked area elastic floor and the best ranked point elastic floor differed significantly $(p<0.001)$. Mean shock absorption differed significantly ( $<<0.001$ ): $56.5 \%$ and $32.2 \%$ for the worst ranked area elastic floor and the best ranked point elastic floor, respectively. Mean vertical deformation differed significantly ( $p$ $<0.001$ ): $3.6 \mathrm{~mm}$ and $2.5 \mathrm{~mm}$ for the worst ranked area elastic floor and the best ranked point elastic floor, respectively. Mean energy restitution differed significantly $(p<0.001)$ : $40.4 \%$ and $62.7 \%$ for the worst ranked area elastic floor and the best ranked point elastic floor, respectively. 


\section{Discussion}

The most important finding of this study is that Dutch elite league male handball players prefer playing on area elastic floors above point elastic floors.

A possible explanation for this lies in the different floor characteristics of these indoor floor types. The top 4 ranked surfaces in Dutch elite handball were area elastic floors, the next six surfaces were point elastic floors. Shock absorption and vertical deformation were twofold higher for area elastic floors compared to point elastic floors. Energy restitution was lower for area elastic floors compared to point elastic floors. Even the worst reported area elastic floor, based on preferences, had significant higher shock absorption and vertical deformation and lower energy restitution compared to the best-reported point elastic floor. No significant difference was found in floor characteristics among area elastic floors or among point elastic floors.

Injury rate in indoor sports may be influenced by differences in floor characteristics and may contribute to a particular preference in floor type among indoor sports players. Studies by Olsen, et al. and Pasanen, et al. found higher injury rates on point elastic floors compared to area elastic floors, in both female and male handball and indoor floorball players $[11,12]$. Both report different shoe-surface traction, a consequence of different ground softening between area and point elastic floors, as possible mechanism for inducing injuries. In line with our findings, area elastic floors react on forces by a relatively large and broad deflection compared to point elastic floors $[14,15]$. This might suggest the material of area elastic floors to better distribute forces acting on the surface compared to point elastic floors. Earlier research that measured floor characteristics of area and point elastic floors, used test methods that are partially similar to the test methods used in our study $[16,17]$. Vertical deformation and energy loss were measured by dropping a weight. Personal preferences in floor types were measured by subjective thoughts. In contrast to the present study, differences in floor characteristics never matched with the results of subjective measurements. This may indicate that test methods used in those studies are not as valid as the Advanced Artificial Athlete apparatus used in our study.

Matching shoes with different floor types might reduce the injury rate among handball players $[11,12]$. However, players may keep using the same shoes for different floor types, due to costs, ease and preference for one particular shoe. Besides, changing shoes may lead to different pressure points and forces acting on the foot and body, contributing to a higher injury vulnerability. From this point, based on the results in this study, it has to be considered to equalize floor characteristics between floors instead of adjusting footwear to different undergrounds as preventive measure.

This study does have some limitations. Firstly, the online survey was a customized version [9]. Therefore, it was not validated and standardized. Besides, participants who filled out the survey could have been biased by injuries in the past due to a particular floor type, influencing their current preference. Secondly, floor covering materials (e.g. stickers, resin and filth) and type of frame underneath the floors (concrete or wooden bars) were not taken into account in measuring floor properties. This could have led to inter-surface characteristic differences. Thirdly, the Triple-A apparatus is officially designed for measuring artificial football and hockey turf surfaces. In this study it is used to measure indoor sports surfaces, containing other mechanical characteristics. Fourthly, this study lacks numbers about injury prevalence in Dutch elite league handball players as well as measures for shoe-surface traction and rotational forces acting on the rotating foot on different floor types. Future research therefore should focus on adding shoe-surface traction and rotatory forces to the measured floor characteristics and monitoring injuries on different playgrounds for a long period in a large population. This could provide evidence about numbers and mechanisms of injuries on different floor types and may give rise to on which specific points preventive measures should be taken to lower the injury rate and associated health costs. In addition, future research should take into account the estimated profit for the handball federation if switching to area elastic surfaces. Besides, exact costs for different floor types and an estimation of healthcare costs due to injuries on different floor types should be included.

The application of point elastic grounds in the Netherlands increased after they were introduced in the 1960s due to increased durability, low investment costs and easiness to maintain [18]. Noteworthy, the present study shows that Dutch elite league male handball players prefer playing on area elastic floors above the point elastic floors. A possible explanation for this lies in the different floor characteristics of these indoor floor types. In the future switching to area elastic flooring may be beneficial. Although a reduction of injuries is not proven, a safer sport surface, especially for young potentials, encourage them to further develop their talent. Even though area elastic floors are more expensive compared to point elastic, investing in area elastic floors may be profitable for the Dutch Handball Federation in preventing injuries. On the other hand, adjusting point elastic floors to meet current characteristics of area elastic floors might also be beneficial. It should be considered to develop point elastic floors with higher shock absorption and vertical deformation and lower energy restitution to better distribute forces acting on the floor.

\section{Conclusion}

Dutch elite league male handball players prefer playing on area elastic floors above point elastic floors. This preference could be explained by the differences in floor characteristics between these floors: higher shock absorption, higher vertical deformation and lower energy restitution in favour of the area elastic floors.

\section{Acknowledgements}

The authors thank the Dutch handball players for participating in this study. Furthermore, we are thankful for the assistance of the team managers and trainers who participated in this study. We thank the court owners for making it possible for us to measure their floor. The study did not receive financial support. 


\section{Disclosure of Interest}

The authors certify that they have no commercial associations (e.g. consultancies, stock ownership, equity interest, patent/licensing arrangements, etc.) that might pose a conflict of interest in connection with the submitted manuscript. The authors report no conflict of interest.

\section{References}

1. Wagner H, Finkenzeller T, Wurth S, et al. (2014) Individual and team performance in team-handball: A review. J Sports Sci Med 13: 808-816.

2. Engebretsen L, Soligard T, Steffen K, et al. (2013) Sports injuries and illnesses during the london summer olympic games 2012. Br J Sports Med 47: 407-414.

3. Junge A, Engebretsen L, Mountjoy ML, et al. (2009) Sports injuries during the summer olympic games 2008. Am J Sports Med 37: 2165-2172.

4. Bere $T$, Bahr R, Popvic N (2020) Mechanisms of injuries in handball. Aspetar - Qatar Orthopedaedic and sports, medicine hospital, Doha, Qatar 142-147.

5. Giroto N, Hespanhol LC, Gomes MRC, et al. (2017) Incidence and risk factors of injuries in brazilian elite handball players: A prospective cohort study. Scand J Med Sci Sports 27: 195-202.

6. Lemoyne J, Poulin C, Richer N, et al. (2017) Analyzing injuries among university-level athletes: Prevalence, patterns and risk factors. J Can Chiropr Assoc 61: 88-95.

7. Moller M, Attermann J, Myklebust G, et al. (2012) Injury risk in Danish youth and senior elite handball using a new SMS text messages approach. Br J Sports Med 46: 531-537.
8. Olsen OE, Myklebust G, Engebretsen L, et al. (2006) Injury pattern in youth team handball: A comparison of two prospective registration methods. Scand J Med Sci Sports 16: 426-432.

9. Clarsen B, Myklebust G, Bahr R (2013) Development and validation of a new method for the registration of overuse injuries in sports injury epidemiology: The Oslo Sports Trauma Research Centre (OSTRC) overuse injury questionnaire. Br J Sports Med 47: 495-502.

10. Pasanen K, Parkkari J, Kannus $P$, et al. (2008) Injury risk in female floor ball: A prospective one-season follow-up. Scand J Med Sci Sports 18: 49-54.

11. Olsen OE, Myklebust G, Engebretsen L, et al. (2003) Relationship between floor type and risk of $A C L$ injury in team handball. Scand J Med Sci Sports 13: 299-304.

12. Pasanen K, Parkkari J, Rossi L, et al. (2008) Artificial playing surface increases the injury risk in pivoting indoor sports: A prospective one-season follow-up study in Finnish female floor ball. Br J Sports Med 42: 194-197.

13. FIFA Quality Concept (2012) Handbook of test methods for football turf 15-29.

14. Yeadon M, Nigg B (1988) A method for the assessment of area-elastic surfaces. Med Sci Sports Exerc 20: 403-407.

15. De Koning J, Nigg B, Gerritsen K (1997) Assessment of the mechanical properties of area-elastic sport surfaces with video analysis. Med Sci Sports Exerc 29: 1664-1668.

16. McMahon TA, Greene PR (1979) The influence of track compliance on running. J Biomech 12: 893-904.

17. Nigg B, Yeadon M (1987) Biomechanical aspects of playing surfaces. J Sports Sci 5: 117-145.

18. Drakos M, Taylor S, Fabricant $P$, et al. (2013) Synthetic playing surfaces and athlete health. J Am Acad Orthop Surg 21: 293-302.

DOI: $10.36959 / 987 / 259$

Copyright: (C 2020 Vluggen TPMJ, et al. This is an open-access article distributed under the terms of the Creative Commons Attribution License, which permits unrestricted use, distribution, and reproduction in any medium, provided the original author and source are credited. 